Running Head: Can Theatre Increase Empathy?

Attending live theatre improves empathy, changes attitudes, and leads to pro-social behavior

\author{
Steve Rathje \\ University of Cambridge \\ Leor Hackel \\ University of Southern California
}

Jamil Zaki

Stanford University

IN PRESS at Journal of Experimental Social Psychology

Please address correspondence to:

Steve Rathje

University of Cambridge

Department of Psychology

Downing Street

Office 406

Cambridge CB2 3EB

srathje@alumni.stanford.edu

Data and materials can be accessed at:

https://osf.io/kcj9t/ 


\section{Attending live theatre improves empathy, changes attitudes, and leads to pro-social behavior}

\section{Abstract:}

Can attending live theatre improve empathy by immersing audience members in the stories of others? We tested this question across three field studies $(n=1622)$, including a pre-registered replication. We randomly assigned audience members to complete surveys either before or after seeing plays, and measured the effects of the plays on empathy, attitudes, and pro-social behavior. After, as compared to before, seeing the plays, people reported greater empathy for groups depicted in the shows, held opinions that were more consistent with socio-political issues highlighted in the shows, and donated more money to charities related to the shows. Seeing theatre also led participants to donate more to charities unrelated to the shows, suggesting that theatre's effects on pro-sociality generalize to different contexts. Altogether, these findings suggest that theatre is more than mere entertainment; it can lead to tangible increases in empathy and pro-social behavior.

Keywords: Theatre, Art, Empathy, Attitudes, Pro-Social 


\section{Attending live theatre improves empathy, changes attitudes, and leads to pro-social}

\section{behavior}

"Theatre teaches us how to understand other people- how to feel empathy for those unlike us." -John Leguizamo, 2018 Tony Awards

Theatre has been a part of people's lives for millennia, and more than 44 million Americans (and many more globally) attend theatre annually (Kushner, 2016). However, the future of theatre is uncertain. Theatre companies across the world have shut down due to the COVID-19 pandemic, and on top of this, there are frequent debates about how much governments should fund the arts and how much schools should make arts a part of their curriculums (Mosle, 2012). Indeed, the US government has repeatedly proposed cutting all government arts funding (Deb, 2017; McGlone, 2020). Adjudicating the role theatre should play in our culture requires understanding the role it plays in our lives. Many advocates of the arts and arts education point to the intangible benefits of theatre, arguing - like Leguizamo - that it can lead to increases in empathy or generosity (Bazalgette, 2017). However, there is currently little experimental evidence to support these claims.

Relevant research has demonstrated that other art forms, such as narrative fiction, can lead to improvements in empathy and social cognition (Dodell-Feder \& Tamir, 2018; Mar \& Oatley, 2008). While much of this research is correlational (Mar et al., 2009), causal evidence also indicates that fiction has effects on empathy, attitudes (Green \& Brock, 2000), out-group prejudice (Mazzocco et al., 2010; Vezzali et al., 2015), and pro-social behavior (Koopman, 2015). Although there have been some notable failed replications in this area (Kidd \& Castano, 2013; see Panero et al., 2016; Samur et al., 2018; Van Kuijk et al., 2018), a meta-analysis of 14 
experiments found that fiction has a small positive causal effect on social cognition (which entails empathy, pro-sociality, theory of mind, and other related constructs) (Dodell-Feder \& Tamir, 2018).

Less research has been conducted with respect to other art forms, such as live theatre. Previous work has found that acting can improve empathy: acting training leads to improvements in empathy and theory of mind in students (Koopman, 2015), and actors tend to score higher on measures of empathy and theory of mind (Goldstein et al., 2009; Nettle, 2006). In terms of attending theatre, correlational evidence suggests that attending performing arts events is associated with empathy and pro-social behavior (Kou et al., 2019; Van de Vyver \& Abrams, 2018), yet there is very little experimental evidence testing the causal effects of live theatre. Of the experiments that have been conducted, most of them featured small-samples of students with a limited number of self-reported outcome variables. For example, one study found that a small sample of middle school students who were randomly assigned to watch a play about the Holocaust reported greater self-reported empathy for individuals who are suffering (Harvey \& Miles, 2009), and another found that middle and high school students who were randomly assigned to see Hamlet or A Christmas Carol showed improvements in social cognition, as measured by the "Reading the Minds in the Eyes" task (Greene, 2015). An additional study found that audience members reported more favorable attitudes about hunting after watching a musical about hunting (Heide et al., 2012). To our knowledge, however, no studies have tested the causal effect of theatre on empathy and pro-social behavior in adults, tested the effects of theatre using behavioral outcome variables, or tested these questions with sufficient power.

It therefore remains unknown whether consuming theatre has a similar impact on empathy as performing theatre or consuming fiction. The effects of acting might be specific to 
the perspective-taking required by playing a character, and the effects of narrative fiction might be specific to reading - for instance, because novels often provide unobservable details about a character's mental life or because reading involves active imaginative processes in the reader. Given the importance of theatre and the arts to the lives of many - now and throughout history this topic warrants much further study within psychology.

To fill this research gap, we conducted multiple high-powered field studies in collaboration with two large regional theatre companies, Artists Repertory Theatre in Portland, OR, and the Public Theatre in New York, with a total of 1,622 participants, including one preregistered replication study. The studies looked at the effects of three different plays. The first was "Skeleton Crew," about auto-workers in Detroit at the start of the great recession; the second was the Pulitzer-Prize winning play "Sweat," about the working class in Reading, Pennsylvania; the third was a new work called "Wolf Play," which is about a lesbian couple adopting a child. While these plays covered different themes and employed different theatrical styles (the first two plays were more realistic, whereas "Wolf Play" incorporated puppetry and experimental elements), they all would be expected to evoke empathy for disadvantaged groups. We included a range of outcome variables, from self-reported empathy for groups depicted in the plays, to attitudes about socio-political issues, to real charitable donation behavior. We also tested the extent to which these effects generalize to contexts beyond the themes explored in the plays - in other words, whether theatre would lead audience members to donate to charities both related to and unrelated to the themes of the shows.

Finally, we explored two potential mechanisms behind theatre's effects. One potential mechanism comes from Narrative Transportation Theory, which suggests that when people are immersed in a story, their attitudes change to reflect those of the story (Green \& Brock, 2000; 
Van Laer et al., 2013). Prior research suggests that those who report being more transported by narratives exhibit more narrative-related attitude and belief change (Mazzocco et al., 2010). We also explored whether empathizing with groups depicted in the show mediated the effect of theatre on socio-political attitudes and pro-social behavior, building on the Empathy-Altruism hypothesis, which suggests that empathy can lead to attitude change (Batson et al., 1997) and pro-social behavior (Batson et al., 2002). It should be noted that empathy and narrative transportation are overlapping constructs, and that empathy for characters in the story is often considered a part of narrative transportation. However, beyond empathy, narrative transportation also measures a general sense of immersion in all characteristics of the story (Green \& Brock, 2000).

\section{Study 1}

For our first study, we examined the effects of the play "Skeleton Crew," which ran at Artists Repertory Theatre, a large regional theatre company in Portland, Oregon from September 2 through 30, 2018. "Skeleton Crew" is a play written by Dominique Morisseau about auto workers in Detroit after the 2008 financial crisis. Alexis Soloski of the New York Times said in a review of the play, "Ms. Morisseau has made it a mission to put onstage people of a race and class and type that much mainstream theater might ignore or demonize. The characters of 'Skeleton Crew' include an unmarried pregnant woman, a gun-packing young man, a middle-age homeless woman" (Soloski, 2015). Because the play sympathetically portrays groups of people that are typically marginalized, we thought this would be a good first show to test the impact of theatre on empathy.

We predicted that this show would lead to an increase in empathy for auto workers in Detroit and would lead to a change in various sociopolitical attitudes related to the show, such as 
greater concern about income inequality. Additionally, we predicted that the show would lead to a greater interest in donating to a charity that supports homelessness in Portland, since the show features a homeless character.

While the above were our key outcome variables of interest, we also tested whether the play could lead to increases in measures of empathy (the interpersonal reactivity index; Davis, 1983) and altruistic values (Smith, 2003). These are typically conceptualized as trait measures, but we were nonetheless interested in whether seeing the play could produce changes in people's self-perceived empathy and altruism. Additionally, we tested whether the play would decrease one's preference for inequality within a society, or social dominance orientation (Pratto et al., 1994), since the play touches on inequality in society.

\section{Method}

Procedure. In a between-subjects field study, we invited audience members to fill out surveys either immediately before or immediately after seeing "Skeleton Crew." At every performance of Artists Repertory Theatre's "Skeleton Crew," which ran from September 2 through 30, 2018, for 30 total performances, study recruitment flyers were inserted in the theatre programs given to audience members before the show. For half of the performances, we instructed audience members to complete the survey immediately before seeing the show. For the other half of performances, we instructed participants to complete the survey immediately after seeing the show. These instructions alternated every other night, and only pre-show or only post-show surveys were given out on any given night. This quasi-experimental design loosely follows the methods of Bushman \& Anderson, (2009), who measured people immediately before or immediately after attending a violent movie at a movie theatre. 
To minimize potential demand effects, participants were not informed that the key manipulation of the experiment was whether they took a survey before or after the show and were not aware that other audience members were taking the survey at different times. Instead, they were simply invited to take a survey about the "beliefs and attitudes" of audience members in exchange for a discount code to purchase future tickets or a free coffee or tea at concessions. Audience members could take this survey either by entering a URL or scanning a QR code and completing the survey on their smartphones or by taking a paper copy of the survey ( 89 audience members filled out paper surveys). All procedures were approved by the University Institutional Review Board. All measures, manipulations, and exclusions are reported within the article.

Participants. Since we aimed to collect the largest sample size possible, our sample size was determined by the number of participants who filled out surveys across the course of the play's run, minus exclusions. For this first study, we did not have a priori predictions of what the effect sizes would be, but since we expected several hundred participants to fill out surveys, we expected that we would have enough power to detect small to medium effect sizes. In total, 803 participants completed the surveys over the course of the run. We excluded 108 participants who 1) did not complete the main outcome variables of the survey, 2) did not complete the survey during the instructed time window, and 3) did not pass an attention check, leaving a total of 695 participants (428 Women, 254 Men, 10 Other/Non-Binary, 3 declined to state, $M_{\text {age }}=61.59, S D$ $=14.70), 352$ of whom completed pre-show surveys and 343 of whom completed post-show surveys. Most participants identified as politically liberal $($ Liberal $=608$, Moderate $=58$, Conservative $=20$ ). A sensitivity power analysis using $G^{*}$ Power (Faul et al., 2007) indicated that this sample size gave us $80 \%$ power to detect an effect size of $d=0.21$, or a "small" effect size 
(Funder \& Ozer, 2019). For every study, all data analysis was conducted only after the final sample was collected.

\section{Measures.}

Attitudes. Participants were asked seven questions about their attitudes about sociopolitical issues related to the show, such as racial discrimination, income inequality, welfare, corporate regulations, wealth redistribution, and affirmative action, adapted from the General Social Survey (see supplementary materials for full questions). Questions were measured on a six-point Likert scale ( 1 = Strongly Disagree; $6=$ Strongly Agree). A composite score of these seven show-related attitude questions was created $(\alpha=0.57, M=5.24, S D=0.74)$.

Charity Interest. Participants were given information about a local homeless shelter in Portland, OR, and were asked how interested they were in this charity, how likely they would be to donate to it, and how likely they would be to volunteer at it. Questions were measured on a six-point Likert scale ( 1 = Strongly Disagree; $6=$ Strongly Agree). These three questions were averaged to create a composite score $(\alpha=0.77, M=3.81, S D=1.08)$.

Interpersonal Reactivity Index (IRI). Participants completed the seven-item Empathic Concern subscale of the Interpersonal Reactivity Index (IRI) (Davis, 1983), a common measure of emotional empathy that includes questions such as "I have tender, concerned feelings for people less fortunate than me" measured on a five-point scale $(1=$ does not describe me very well; $5=$ describes me very well $)(\alpha=0.77, M=4.26, S D=0.60)$. They also completed the seven-item Perspective Taking subscale of the IRI (Davis, 1983), a common measure of cognitive empathy that includes questions such as "I try to understand my friends better by imagining how things look from their perspective" measured on a five-point scale $(1=$ does not describe me very well; $5=$ describes me very well $)(\alpha=0.79, M=3.83, S D=0.66)$. 
Topic-Specific Empathy. Two questions from the Empathic-Concern subscale of the IRI were revised to apply to factory workers in Detroit after the 2008 financial crisis (e.g., "I have tender, concerned feelings for factory workers in Detroit"), creating a topic-specific empathic concern measure $(\alpha=0.67, M=4.07, S D=0.87)$. Two questions from the Perspective-Taking subscale of the IRI (e.g., "I can understand the lives of factory workers in Detroit by imagining how things look from their perspective") were used to create a topic-specific empathic concern measure $(\alpha=0.54, M=3.91, S D=0.86)$. The four questions were also combined to create a general measure of topic-specific empathy $(\alpha=0.74, M=3.99, S D=0.77)$.

Social Dominance Orientation. Participants completed the eight-item short-form Social Dominance Orientation scale (Pratto, Sidanius, Stallworth \& Malle, 1994), which measures one's preference for hierarchy and inequality among social groups, including questions such as "some groups of people are simply inferior to others" $(\alpha=0.79, M=1.86, S D=0.62)$.

Altruistic Values. Participants completed the four-item Altruistic Values scale (Smith, 2003), which measures a propensity to help others (e.g., "personally assisting people in trouble is very important to me") $(\alpha=0.64, M=4.41, S D=0.70)$.

Narrative Transportation. Participants who completed the post-show survey were given six-item short-form Narrative Transportation Scale (Appel, Gnambs, Richter, \& Green, 2015), which measures how immersed people felt in a narrative (e.g., "The play affected me emotionally") $(\alpha=0.75, M=3.81, S D=1.08)$. Participants who completed the pre-show survey were not given this measure, as it was not relevant to those who had not yet seen the show.

Demographics. Participants were asked their age, gender, household size, income, political orientation ( 1 = Extremely Liberal, 6 = Extremely Conservative), and how frequently 
they attend the theatre $(1=$ Very Infrequently, $6=$ Very Frequently $)$ See supplementary materials for complete wording of all demographic questions.

All measures, de-identified data and analysis code are available at:

\section{https://osf.io/kcj9t/.}

\section{Results}

Main Outcome Variables. As predicted, participants who filled out the post-show survey reported feeling more empathy toward factory workers in Detroit $\left(M_{\text {post }}=4.21,95 \% \mathrm{CI}=\right.$ $[4.15,4.29])$ than participants in the pre-show condition $\left(M_{\text {pre }}=3.77,95 \% \mathrm{CI}=[3.69,3.86]\right)$, $\mathrm{t}(693)=7.95, p<0.001, d=0.60$ (See Figure 1A). Specifically, they reported feeling more empathic concern for factory workers in Detroit $\left(M_{\text {post }}=4.33,95 \% \mathrm{CI}=[4.25,4.41] \mathrm{vs} . M_{\text {pre }}=\right.$ $3.82,95 \% \mathrm{CI}=[3.72,3.91]), t(677)=8.20, p<0.001, d=0.62$; and were more willing to take their perspectives $\left(M_{\text {post }}=4.10,95 \% \mathrm{CI}=[4.02,4.18]\right.$ vs. $\left.M_{\text {pre }}=3.73,95 \% \mathrm{CI}=[3.63,3.83]\right)$, $t(678)=5.79, p<0.001, d=0.44$.

Did the play lead people to change their socio-political attitudes about issues related to the show? Participants who filled out the survey after watching the show expressed more showrelated attitudes $\left(M_{\text {post }}=5.34,95 \% \mathrm{CI}=[5.28,5.41]\right)$ than participants who filled out the survey before watching the show $\left(M_{\mathrm{pre}}=5.14,95 \% \mathrm{CI}=[5.05,5.22]\right), t(668)=3.78, p<0.001, d=0.29$ (See Figure $1 B$ ). In particular, participants in the post-show condition were more likely to think that racial discrimination is a major issue $\left(M_{\text {post }}=5.72,95 \% \mathrm{CI}=[5.65,5.80]\right.$ vs. $M_{\text {pre }}=5.46$, $95 \% \mathrm{CI}=[5.36,5.56]), t(569)=4.48, p<0.001, d=0.33$; that unions are important $\left(M_{\text {post }}=\right.$ $5.33,95 \% \mathrm{CI}=[5.23,5.43]$ vs. $\left.M_{\text {pre }}=5.14,95 \% \mathrm{CI}=[5.02,5.26]\right), t(693)=2.46, p=0.014, d=$ 0.18 ; that the government should increase welfare spending $\left(M_{\text {post }}=5.03,95 \% \mathrm{CI}=[4.93,5.12]\right.$ vs. $\left.M_{\text {pre }}=4.83,95 \% \mathrm{CI}=[4.73,4.94]\right), t(691)=2.66, p=0.008, d=0.21 ;$ that the government 
should reduce income disparities $\left(M_{\text {post }}=5.33,95 \% \mathrm{CI}=[5.22,5.45]\right.$ vs. $M_{\text {pre }}=5.03,95 \% \mathrm{CI}=$ $[4.90,5.18]), t(672)=3.21, p=0.001, d=0.25$; and were more supportive of corporate regulations $\left(M_{\text {post }}=5.19,95 \% \mathrm{CI}=[5.09,5.28]\right.$ vs. $\left.M_{\text {pre }}=4.92,95 \% \mathrm{CI}=[4.79,5.05]\right), t(691)=$ 2.95, $p=0.003, d=0.23$. There was a marginally significant increase in pro-affirmative action beliefs $\left(M_{\text {post }}=5.09,95 \% \mathrm{CI}=[4.99,5.19]\right.$ vs. $\left.M_{\text {pre }}=4.94,95 \% \mathrm{CI}=[4.82,5.06]\right), t(673)=$ $1.90, p=0.058, d=0.14$; and a marginal increase in the belief that income inequality is a major issue $\left(M_{\text {post }}=5.72,95 \% \mathrm{CI}=[5.65,5.80]\right.$, vs. $\left.M_{\text {pre }}=5.61,95 \% \mathrm{CI}=[5.52,5.70]\right) t(672)=1.91$, $p=0.056, d=0.14$.

Did the play make participants more interested in charitable giving? Participants were also more interested in donating to the homeless shelter after seeing the show $\left(M_{\text {post }}=3.98,95 \%\right.$ $\mathrm{CI}=[3.87,4.08])$ than before seeing the show $\left(M_{\text {pre }}=3.66,95 \% \mathrm{CI}=[3.54,3.78]\right) t(668)=4.41$, $p<0.001, d=0.30$ (See Figure 1C).

Altogether, watching the play led people to feel more empathy for factory workers in Detroit, changed people's attitudes about a number of socio-political issues related to the show, and made people more interested in supporting a local homeless shelter, as shown in Figure 1.
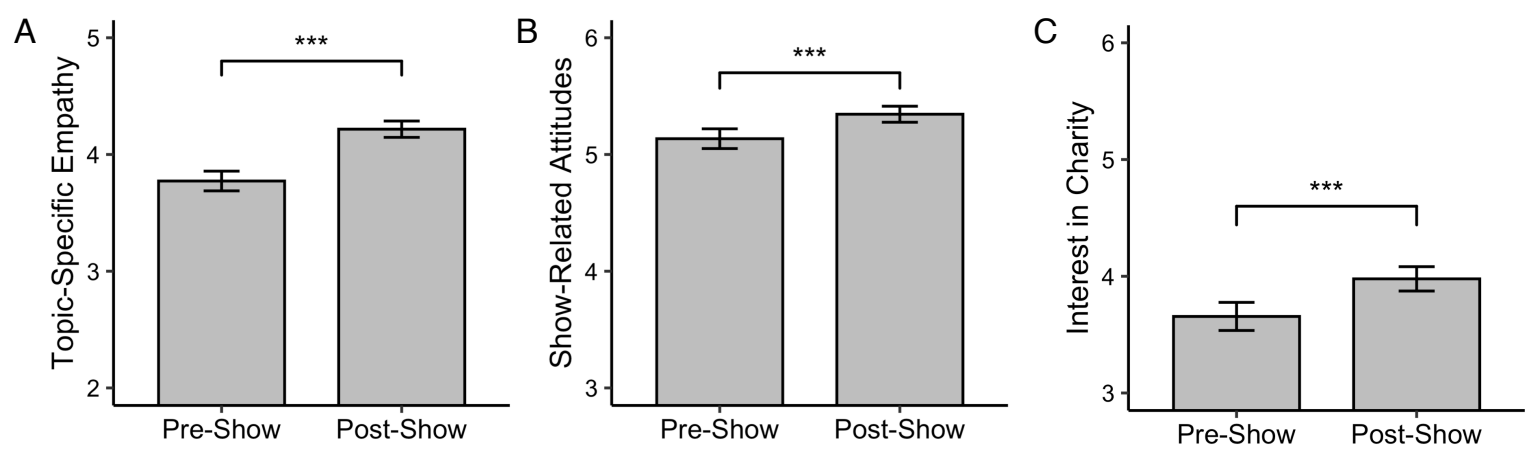

Figure 1. Effect of the play on A) empathy for Detroit factory workers, B) show-related attitudes, and C) interest in supporting a local homeless shelter. Empathy is measured on a scale from 1 to 5. Attitudes and Charity are measured on a scale from 1 to 6. Error bars represent standard errors. 
Trait outcome variables. While the play increased participants' empathy for factory workers in Detroit, it did not have an effect on trait levels of empathic concern $\left(M_{\text {post }}=4.30,95 \%\right.$ $\mathrm{CI}=[4.24,4.36]$ vs. $\left.M_{\text {pre }}=4.22,95 \% \mathrm{CI}=[4.16,4.29]\right), t(693)=1.69, p=0.091, d=0.13$, or perspective-taking $\left(M_{\text {post }}=3.80,95 \% \mathrm{CI}=[3.73,3.86]\right.$ vs. $\left.M_{\text {pre }}=3.85,95 \% \mathrm{CI}=[3.77,3.92]\right)$, $t(693)=1.05, p=0.30, d=0.08$. However, since these are trait measures that measure how much empathy people experience in their daily lives, they may be unlikely to change in a short time period.

The play did, however, decrease participants' levels of social dominance orientation, or preference for inequality in society $\left(M_{\text {post }}=1.79,95 \% \mathrm{CI}=[1.72,1.86]\right.$ vs. $M_{\text {pre }}=1.93,95 \% \mathrm{CI}$ $=[1.86,2.00]), t(686)=2.78, p=0.01, d=0.21$. Additionally, seeing the play led to higher levels of altruistic values, (i.e., agreement with questions such as "people should be willing to help others who are less fortunate" $)\left(M_{\text {post }}=4.48,95 \% \mathrm{CI}=[4.41,4.47]\right.$ vs. $M_{\text {pre }}=4.35,95 \% \mathrm{CI}$ $=[4.27,4.42]), t(692)=2.55, p=0.01, d=0.19$.

Are people who see theatre more frequently more empathetic? We examined the bivariate relationships between the question "how often do you see theatre?" and the main outcome variables. Frequency of attending the theatre had small positive correlations with an interest in charity $r(693)=0.08,95 \% \mathrm{CI}=[-0.02,0.17], p=0.046$, and empathic concern $r(693)=0.09$, $95 \% \mathrm{CI}=[0.01,0.17], p=0.020$, but not perspective-taking, $r(693)=-0.02,95 \% \mathrm{CI}=[-0.09$, $0.062], \mathrm{p}=0.678$, social dominance orientation, $r(693)=-0.05,95 \% \mathrm{CI}=[-0.12,0.02]$, or topicspecific empathy, $r(693)=0.07,95 \% \mathrm{CI}=[-0.02,0.15], \mathrm{p}=0.067$.

Narrative Transportation. Next, we examined potential mechanisms behind these effects. First, we examined the link between how transported people felt by the show and our main outcome variables among participants who completed the post-show survey. Narrative 
transportation was significantly correlated with all of the key outcome variables, such as showrelated attitudes, $r(341)=0.22,95 \% \mathrm{CI}=[0.13,0.31], p<0.001$, empathy for factory workers in Detroit, $r(341)=0.34,95 \% \mathrm{CI}=[0.23,0.45], p<0.001$, trait empathic concern, $r(341)=0.30$, $95 \% \mathrm{CI}=[0.20,0.40], p<0.001$, trait perspective-taking. $r(341)=0.15,95 \% \mathrm{CI}=[0.04,0.27]$, $p=0.005$, interest in the charity, $r(341)=0.26,95 \% \mathrm{CI}=[0.16,0.35] p<0.001$, altruism $r(341)$ $=0.27,95 \% \mathrm{CI}=[0.17,0.36], p<0.001$, and social dominance orientation $r(341)=-0.32,95 \%$ $\mathrm{CI}=[-0.41,-0.22], p<0.001$.

Empathy as a Mediator. We also examined whether participants' levels of empathy for groups depicted in the show mediated the effect of seeing theatre on attitude change and interest in charity. Results indicated that theatre was a significant predictor of empathy, $B=0.22,95 \% \mathrm{CI}$ $=[0.17,0.28], p<0.001$, and that empathy was a significant predictor of attitudes, $B=0.31,95 \%$ $\mathrm{CI}=[0.24,0.38], p<0.001$. Theatre was no longer a predictor of attitudes when controlling for empathy, $B=0.04,95 \% \mathrm{CI}=[-0.02,0.09], p=0.18$, indicating that empathy fully mediated theatre's effects on empathy. The indirect effect was tested using a percentile bootstrap estimation approach with 1000 samples (Hayes, 2017). The indirect coefficient was significant, $B=0.068,95 \% \mathrm{CI}=[0.063,0.13]$. Thus, empathy fully mediated the effects of theatre on sociopolitical attitudes.

Likewise, another mediation analysis revealed that theatre significantly predicted empathy, $B=0.22,95 \% \mathrm{CI}=[0.17,0.28], p<0.001$, which in turn significantly predicted interest in supporting the charity, $B=0.33,95 \% \mathrm{CI}=[0.22,0.43], p<0.001$. Theatre was still a significant predictor of charity interest when controlling for empathy $B=0.089,95 \% \mathrm{CI}=[0.01$, $0.17], p=0.032$, suggesting that empathy partially mediated the effects of theatre on interest in supporting the charity. The indirect coefficient was significant, $B=0.072,95 \% \mathrm{CI}=[0.041$, 
0.097]. In sum, an increase in empathy mediated both this play's effects on socio-political attitudes and interest in supporting a local charity. While mediation analysis is correlational and cannot determine causality when variables are measured rather than manipulated (Fiedler et al., 2011; Spencer et al., 2005), this analysis is consistent with the interpretation that theatre changes people's attitudes in part by increasing their empathy for characters in the show. Additionally, we also recognize that there could also be alternative mediators behind this effect (Fiedler et al., 2018).

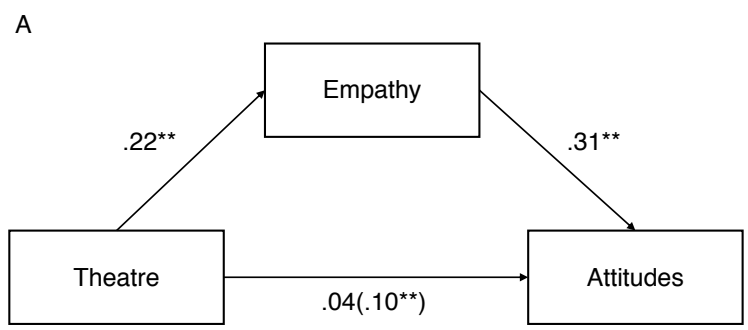

Indirect Effect: $B=0.068, \mathrm{SE}=0.013,95 \% \mathrm{Cl}=[0.063,0.13]$

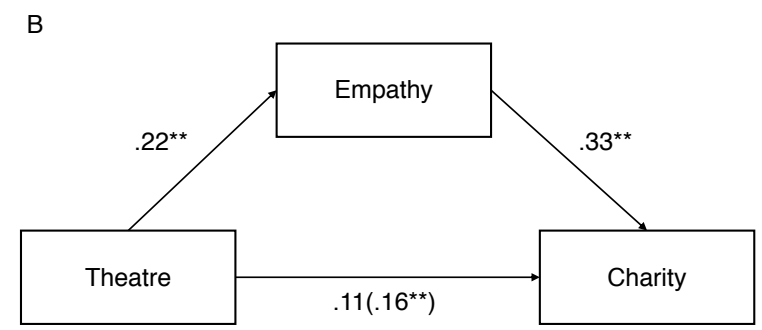

Indirect Effect: $B=0.072, \mathrm{SE}=0.015,95 \% \mathrm{Cl}=[0.041,0.097]$

Figure 2. Empathy for Detroit factory workers A) fully mediated theatre's effects on sociopolitical attitudes, and B) partially mediated theatre's effects on interest in donating to or volunteering at a local homeless shelter.

\section{Discussion}

After seeing the play "Skeleton Crew," audience members reported feeling more empathy for factory workers in Detroit, changed their attitudes about a number of socio-political issues related to the show, and expressed more interest in donating to or volunteering at a local charity that supports homeless individuals. The play also led to lower preference for inequality in society (social dominance orientation) and a greater concern for helping others (altruistic values), though it did not change levels of trait empathic-concern or perspective-taking. Lastly, empathy mediated the effects of theatre on attitude change and interest in charity, and narrative 
transportation correlated with the main outcome variables, providing correlational evidence that empathy and narrative transportation are two potential mechanisms behind these effects.

\section{Study 1b}

\section{Methods}

Overview. A smaller-scale study ran concurrently with Study 1 in collaboration with the Public Theatre, a large nonprofit theatre company in New York. The Public Theatre conducted an 18-show tour of the Pulitzer Prize-winning play "Sweat" through various cities in the U.S. Midwest (in Pennsylvania, Ohio, Michigan, Wisconsin, and Minnesota) from September 24 through October 18, 2018. This play addresses many similar themes to "Skeleton Crew," looking at the lives of factory workers in Reading, Pennsylvania — one of the poorest towns in America. According to Oscar Eustis, artistic director of the Public Theatre, the major arts and cultural institutions exist mainly in the liberal, coastal parts of the United States, and this tour was designed to allow theatre to reach parts of the country that do not normally attend theatre (Eustis, 2018). Thus, this study gave us the opportunity to test the effects of theatre in a more rural, potentially less liberal population, and test whether the effects of theatre are different for less liberal audience members.

Participants completed surveys included in pre-show or post-show emails sent out by the Public Theatre either before the show or two days after the show. Participants were instructed to take the surveys within 48 hours of receiving the email. Sample size was once again determined by the number of participants who filled out the survey, minus exclusions. In total, 336 participants completed the survey, and we excluded 28 participants who did 1) did not finish our main outcome variables, and 2) did not complete the survey during the instructed time window, leaving a total of 308 participants $\left(\right.$ Male $=84$, Female $=218$, Non-Binary $=6, M_{\text {age }}=53.34, S D$ 
$=16.58$, Pre-Show $=195$, Post-Show $=113)$. This analysis had $80 \%$ power to detect an effect size of $d=0.33$. The sample was still mostly liberal, but slightly more politically diverse than the sample in Study $1($ Liberal $=239$, Moderate $=46$, Conservative $=23)$. In a shorter survey, participants were asked about show-related attitudes $(\alpha=0.86, M=4.99, S D=0.75)$, and empathy for "factory workers whose longtime jobs disappear" $(\alpha=0.70, M=4.21, S D=0.74)$. Participants in the post-show condition were given the narrative transportation scale $(\alpha=0.64, M$ $=5.34, S D=0.55)$.

\section{Results}

Main Outcome Variables. The show led to a marginally significant increase in in beliefs related to the themes of the show $\left(M_{\text {post }}=5.09,95 \% \mathrm{CI}=[4.97,5.21]\right.$ vs. $M_{\text {pre }}=4.94,95 \% \mathrm{CI}=$ $[4.83,5.05]), \mathrm{t}(306)=1.78, p=0.076, d=0.20$. It also led to a non-significant trend on empathy in the hypothesized direction $\left(M_{\text {post }}=4.28,95 \% \mathrm{CI}=[4.15,4.42]\right.$ vs. $M_{\text {pre }}=4.17,95 \% \mathrm{CI}=$ $[4.13,4.29]), t(306)=1.35, p=0.178, d=0.16$. Narrative transportation was once again correlated with both show-related attitudes, $r(111)=0.32,95 \% \mathrm{CI}=[0.10,0.50], p<0.001$, and empathy for factory workers, $r(111)=0.25,95 \% \mathrm{CI}=[0.03,0.46], p=0.008$.

Political Orientation as a Moderator. To test the possibility that political diversity could have affected the results, we ran exploratory moderation analyses to see whether political orientation (measured on a 6-point scale from "very liberal" to "very conservative") moderated the effect of theatre on empathy and attitudes. The first moderation analyses indicated that political orientation did not moderate the effect of theatre on empathy, $B=0.02,95 \% \mathrm{CI}=[-$ $0.05,0.09], p=0.566$. However, the second moderation model found that theatre significantly predicted attitudes, $B=0.03,95 \% \mathrm{CI}=[0.01,0.13], p=0.028$, political orientation significantly predicted attitudes, $B=-0.40,95 \% \mathrm{CI}=[-0.45,-0.35], p<0.001$, and there was a significant 
interaction between political orientation and attitudes, $B=0.05,95 \% \mathrm{CI}=[0.00,0.10], p=$ 0.042. The interaction plot (see supplementary materials) indicated that theatre had a greater impact for more conservative, as compared to liberal, participants.

To follow-up on these results, we conducted a median split on the variable of political orientation, and found that the more conservative half of participants displayed a significant difference in attitudes from the pre-show to post-show conditions $\left(M_{\text {post }}=4.62,95 \% \mathrm{CI}=[4.41\right.$, $4.84]$ vs. $\left.M_{\text {pre }}=4.22,95 \% \mathrm{CI}=[4.02,4.41]\right) t(101)=2.72, p=0.008, d=0.57$, but this was not the case for the more liberal half of participants $\left(M_{\text {post }}=5.32,95 \% \mathrm{CI}=[5.21,5.43]\right.$ vs. $M_{\text {pre }}=$ $5.30,95 \% \mathrm{CI}=[5.21,5.39]), t(203)=0.778, d=0.04$. Further results are reported in the supplement.

\section{Discussion}

While this study had less power to detect smaller effect sizes, and participants completed post-show surveys 2 days after (rather than immediately after) the performance, the results trended in the hypothesized direction, and we included this data in our internal meta-analysis and table of effect sizes (Table 1 and Table 2). Furthermore, this study gave us the chance to test the effects of theatre in a more politically diverse population. Exploratory analyses found that political orientation moderated the effect of theatre on empathy, such that theatre was more effective in changing attitudes for the more conservative participants. The fact that theatre was effective for changing the attitudes of more conservative participants goes against the idea that theatre is simply "preaching to the choir" by simply expressing liberal attitudes to liberal audiences. Although it is true that liberals attend theatre more often than conservatives, theatre appears to be effective at changing the attitudes of both liberal and conservative theatregoers (and may even be more effective for conservatives). 


\section{Study 2}

We conducted a high-powered, pre-registered replication of the main findings of Study 1 and the suggestive findings of Study $1 \mathrm{~b}$ in the context of another play. Additionally, since Study 1 found that seeing a play led to an increase in self-reported intentions to give to charity, we wanted to see if the play led to an increase in actual donation behavior. Our three main preregistered hypotheses were that seeing a play would once again 1) change people's attitudes about socio-political issues related to the show, 2) lead to an increase in empathy for groups depicted in the show, and 3) lead to an increase in donation behavior to a charity related to the show. The pre-registration is available here: http://aspredicted.org/blind.php? $\mathrm{x}=423 \mathrm{xz} 3$. Furthermore, we wanted to see if this increase in donation behavior extended to a charity unrelated to the show to test whether theatre can lead to a more generalizable sense of prosociality.

\section{Methods.}

Procedure. The specific show we tested was called "Wolf Play" by Hansol Jung, which ran at Artists Repertory Theatre from March 10 through April 7, 2019. "Wolf Play" tells the story of a same-sex couple trying to adopt a child, and once again features characters who may typically be marginalized, making the play another good test of theatre's effects on empathy. Indeed, a review of the play said, "Great theatre takes you out of yourself. It gives you empathy for people who are different from you and helps you understand the world from a perspective that's not your own. That's exactly what Wolf Play does" (Garver, 2019). Replicating the methods of Study 1, pre-show and post-show surveys were disseminated at every performance of "Wolf Play," with pre-show and post-show surveys alternating at every other performance. 
Participants. We conducted a power analysis using $\mathrm{G}^{*}$ Power to estimate sample sizes needed to detect effects similar to those in Study 1. The smallest effect size for one of our main outcome variables in Study 1 was $d=0.29$ (for the "attitudes" variable). If we expected a similar effect size, the power analysis indicated that we would need a sample size of 518 to detect an effect with $95 \%$ power. Since we expected to collect a larger sample size similar to that in Study 1, we expected to have high power to test our hypotheses.

Across all performances, 699 participants completed the surveys, and we once again excluded participants who 1) did not complete the main outcome variables of the survey, 2) did not complete the survey during the instructed time window, and 3) did not pass an attention check, leaving a total of 619 participants (193 Men, 375 Women, 12 Transgender/NonBinary/Other, $\left.M_{a g e}=55.22, S D=18.54\right)$. Of these, 323 participants filled out pre-show surveys and 296 filled out post-show surveys. This analysis had 80\% power to detect an effect size of $d=$ 0.23. Ninety-five of the audience members chose to take a paper copy of the survey. The sample was once again mostly liberal (Liberals $=547$, Moderate $=26$, Conservative $=16$ ).

\section{Measures.}

Attitudes. Participants were again asked five questions about social and political opinions related to the show, such as the belief that same-sex couples can raise children as well as heterosexual couples, the belief that the foster care system should be improved, and the beliefs that sexism, racial discrimination, and discrimination against the LGBTQ community are important issues $(\alpha=0.78, M=5.55, S D=0.59)$.

Topic-Specific Empathy. Two questions from the empathic concern and two from the perspective-taking subscales of the IRI were adapted to create a four-item composite measuring empathic concern for same-sex couples trying to start a family (e.g., "I have tender, concerned 
feelings for same-sex couples trying to start a family") $(\alpha=0.69, M=4.10, S D=0.76)$. These same four questions were adapted to create a composite measure of empathy for children in foster care $(\alpha=0.59, M=3.99, S D=0.69)$.

Charitable Donation Behavior. Participants were given information about a charity related to the themes of the show and a charity unrelated to the themes of the show in randomized order. The related charity was a Portland-based charity called "With Love" that supports children in foster care. The unrelated charity was the Portland-based chapter of "Meals on Wheels," which supports senior citizens. After reading about each charity, participants were told that they would be entered in a lottery where they would receive a \$25 Amazon gift card if they won. However, they were also given the option to allocate a portion of that $\$ 25$ to the charity with a sliding scale.

Repeated Outcome Variables. As in Study 1, participants were also given the 8-item Social Dominance scale $(\alpha=0.76, M=1.67, S D=0.62)$, the four-item Altruistic Values scale $(\alpha$ $=0.64, M=5.07, S D=0.69)$, and the six-item Narrative Transportation Scale $(\alpha=0.71, M=$ 5.18, $S D=0.68)$, and the same demographic questions.

\section{Results}

For all analysis, we used a Bonferroni corrected alpha level of 0.016 to account for testing 3 main hypotheses, as specified in our pre-registration.

Main outcome variables. Did the play increase empathy for groups depicted in the show? As predicted, participants in the post-show condition scored significantly higher on the topic-specific empathy measure $\left(M_{\text {post }}=4.12,95 \% \mathrm{CI}=[4.05,4.19]\right)$ than participants in the preshow condition $\left(M_{\mathrm{pre}}=3.98,95 \% \mathrm{CI}=[3.91,4.04]\right), t(617)=2.87, p=0.004, d=0.23($ Figure $3 A$ ). When splitting up this composite measure into the empathy for same-sex parents and 
empathy for children in foster care measures, we found significant effects for same-sex parents $\left(M_{\text {post }}=4.19,95 \% \mathrm{CI}=[4.10,4.27]\right.$ vs. $\left.M_{\text {pre }}=4.02,95 \% \mathrm{CI}=[3.93,4.09]\right), t(617)=2.83, p=$ $0.005, d=0.23$, and marginally significant effects for children in foster care $\left(M_{\text {post }}=4.04,95 \%\right.$ $\mathrm{CI}=[3.96,4.14]$ vs. $\left.M_{\text {pre }}=3.94,95 \% \mathrm{CI}=[3.86,4.01]\right), t(617)=1.95, p=0.052, d=0.15$.

Did the show change people's attitudes about socio-political issues? Contrary to expectations, participants who completed the survey after the show did not change their attitudes $\left(M_{\text {post }}=5.57,95 \% \mathrm{CI}=[5.51,5.62]\right.$ vs. $\left.M_{\text {pre }}=5.54,95 \% \mathrm{CI}=[5.47,5.61]\right), t(617)=0.56, p=$ $0.573, d=0.05$ (Figure $3 B$ ). Looking at each of the individual attitude questions, participants in the post-show condition were more supportive of improving the foster care system $\left(M_{\text {post }}=5.90\right.$, $95 \% \mathrm{CI}=[5.87,5.94])$ than participants in the pre-show condition $(M=5.79,95 \% \mathrm{CI}=[5.81$, $5.88]), t(513)=3.05, p=0.002, d=0.24$, but none of the responses to the other attitude questions changed (See Supplementary Materials). However, responses to the attitude questions were skewed (Skewedness $=-2.467, S E=0.098$, Kurtosis $=9.580, S E=0.196)$, with $\operatorname{most}$ participants expressing extremely high agreement with all of the attitude questions $(M=5.55$ on a 1-6 scale). Because of this strong skewness, the ability for us to detect an effect on the independent variable may have been compromised by ceiling effects (Hessling et al., 2004). The results did not change when log-transformed tests were conducted (See Supplementary Materials).

We then looked at the play's effect on charitable donations to both the related and unrelated charity. As predicted, participants in the post-show condition donated significantly more to the show-related charity $\left(M_{\text {post }}=21.76,95 \% \mathrm{CI}=[20.92,22.60]\right)$ than participants in the pre-show condition $\left(M_{\text {post }}=20.07,95 \% \mathrm{CI}=[19.19,21.03]\right), t(612)=2.60, p=0.009, d=0.21$. Interestingly, this effect generalized to the unrelated charity $\left(M_{\text {post }}=21.89,95 \% \mathrm{CI}=[21.05\right.$, 
$22.73]$ vs. $\left.M_{\text {pre }}=19.23,95 \% \mathrm{CI}=[18.21,20.35]\right), t(598)=3.96, p<0.001, d=0.32$. Because the effect appeared to be stronger for the unrelated charity, we conducted a 2 (charity type) $\times 2$ (preshow or post-show) repeated measures ANOVA on donation amount, and found a marginally significant interaction, $F(1,613)=4.12, p=0.043, \eta_{\mathrm{p}}{ }^{2}=0.01$. It is unclear why donations increased more for the unrelated charity than the related one. Perhaps this greater increase may have been due to the fact that the mean donation to the unrelated charity began at a lower starting point and was thus less susceptible to ceiling effects. Nonetheless, these results demonstrate that people who watch theatre not only report intentions to donate to charity but also do so when given the opportunity, even when the charity is unrelated to the themes of the show.
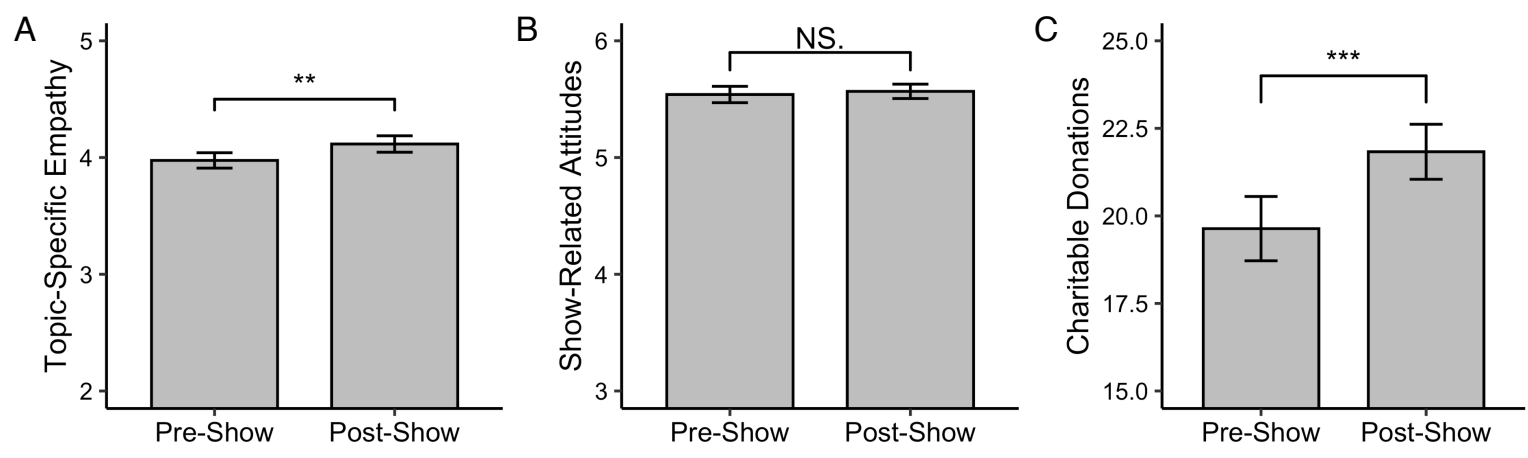

Figure 3. Effect of the play on A) empathy for groups depicted in the show, B) attitudes related to the show, and C) donations to charity. A composite score of empathy for the two groups (same-sex parents and children in foster care) and the two charities (related and unrelated) are shown. Empathy is measured on a scale from 1 to 5, Attitudes are measured on a scale from 1 to 6 , and charitable donations are measured on a scale from 0 to 25 . Error bars represent standard errors.

Trait Outcome Variables. The play did not affect social dominance orientation $\left(M_{\text {post }}=\right.$ $1.63,95 \% \mathrm{CI}=[1.56,1.71]$ vs. $\left.M_{\text {pre }}=1.70,95 \% \mathrm{CI}=[1.63,1.77]\right) t(603)=1.29, p=0.20, d=$ 0.10 , and it led to a marginal increase in altruistic values $\left(M_{\text {post }}=5.13,95 \% \mathrm{CI}=[5.05,5.20]\right.$ vs. $\left.M_{\text {pre }}=5.02,95 \% \mathrm{CI}=[4.94,5.10]\right), t(610)=1.83, p=0.067, d=0.15$. Thus, we did not replicate 
Study 1's findings regarding social dominance orientation and altruistic values, though the means were trending in the same direction.

Frequency with which participants attended the theatre was marginally correlated with altruistic values, $r(597)=0.081,95 \% \mathrm{CI}=[0.02,0.17], p=0.049,($ all other $p s>0.083)$. Since we did not measure trait empathic concern in this sample, we could not replicate the previous positive correlation between empathic concern and frequency of attending theatre.

Narrative Transportation. Consistent with the results of Study 1, narrative transportation was significantly correlated with most of our main outcome variables among those who completed the post-show survey, such as show-related attitudes, $r(290)=0.32,95 \% \mathrm{CI}=$ $[0.20,0.44], p<0.001$, empathy for children in foster care, $r(290)=0.34,95 \% \mathrm{CI}=[0.22,0.46]$, $p<0.001$, empathy for same-sex parents, $r(290)=0.43,95 \% \mathrm{CI}=[0.32,0.54], p<0.001$, donations to the unrelated charity, $r(290)=0.19,95 \% \mathrm{CI}=[0.07,0.33], p<0.001$, altruistic values, $r(290)=0.30,95 \%=[0.17 .0 .42], p<0.001$, and social dominance orientation, $r(290)=$ $0.36,95 \% \mathrm{CI}=[-0.46,-0.26], p<0.001)$. Unexpectedly, it was unrelated to donations to the related charity $(r=0.08,95 \% \mathrm{CI}=[0.03,0.21], p=0.135)$.

Empathy as a Mediator. We then ran our pre-registered mediation analysis. As in Study 1, theatre was a significant predictor of empathy, $B=0.07,95 \% \mathrm{CI}=[0.02,0.12], p=0.004$, empathy was a significant predictor of attitudes, $B=0.31,95 \% \mathrm{CI}=[0.24,0.39], p<0.001$, and theatre was not a predictor of attitudes when controlling for empathy, $B=-0.01,[-0.05,0.04], p$ $=0.711$. The indirect coefficient was significant, $B=0.02,95 \% \mathrm{CI}=[0.01,0.04]$, showing that there was an indirect effect of theatre on attitudes through empathy, even though there was not a direct effect. While this provides suggestive evidence for empathy as a mediator, caution is 
advised in interpreting mediation analysis, as other interpretations of this effect are possible (Fiedler et al., 2018).

We also tested whether empathy mediated theatre's effects on charitable donation behavior. For this analysis, we used the composite score of the two charities. Again, as in Study 1, theatre significantly predicted empathy, $B=0.07,95 \% \mathrm{CI}=[0.02,0.12], p=0.004$, empathy significantly predicted donation behaviors, $B=1.96,95 \% \mathrm{CI}=[0.98,2.95], p<0.001$, and theatre was still a significant predictor of donation behavior when controlling for attitudes, $B=$ $0.96,95 \% \mathrm{CI}=[0.35,1.57], \mathrm{p}=0.001$, consistent with partial mediation. The indirect coefficient was significant, $B=0.14,95 \% \mathrm{CI}=[0.04,0.27]$, showing that empathy once again mediated the effect of theatre on charitable donation behavior. The results were the same when looking at only the related charity $(B=0.11, \mathrm{SE}=0.05,95 \% \mathrm{CI}=[0.02,0.23])$ and the unrelated charity $(B=$ $0.17, \mathrm{SE}=0.08,95 \% \mathrm{CI}=[0.05,0.34]) . \mathrm{In}$ sum, we replicated Study 1 's effects regarding empathy as a mediator of theatre's effects on attitudes and charitable donation behavior, providing further evidence that theatre may lead to attitude change and pro-social behavior by evoking empathy for groups depicted in the plays.

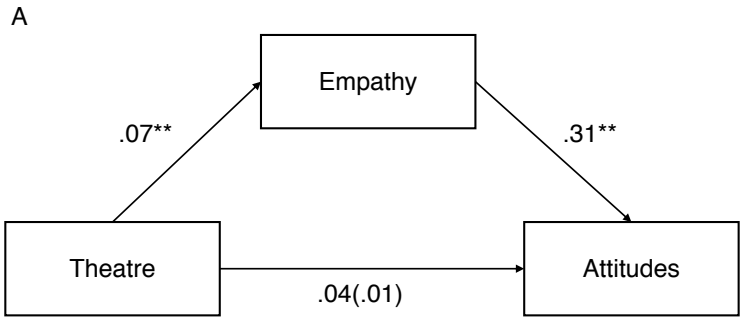

Indirect Effect: $B=0.02, S E=0.01,95 \% \mathrm{Cl}=0.01,0.04$

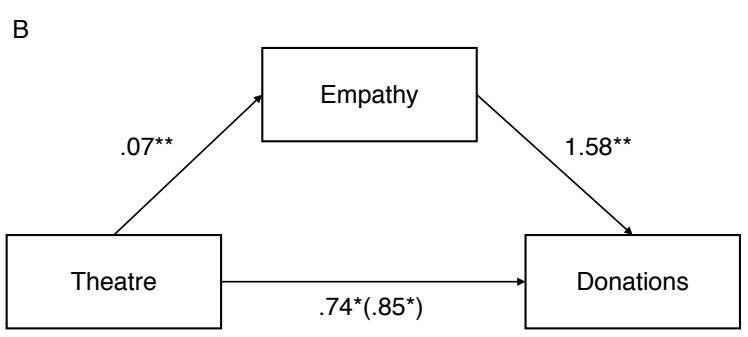

Indirect Effect: $B=0.11, S E=0.05,95 \% \mathrm{Cl}=0.02,0.23$

Figure 4. Replicating the mediation analysis in Study 1, theatre A) mediated theatre's effects on attitudes, even though there was no direct effect, and B) partially mediated theatre's effects on charitable donation behavior.

\section{Discussion}


We replicated Study 1's effects regarding theatre's effects on empathy. Extending the findings of Study 1, we also found that theatre not only leads to self-reported intentions to donate, but also led to actual donation behavior. Furthermore, we found that this effect generalized to an unrelated charity, suggesting that theatre can lead to a broader sense of generosity outside of the context of the particular show. We also replicated Study 1's results suggesting that empathy and narrative transportation may play a role in these effects.

While the play changed people's beliefs about improving the foster care system, it did not change any other show-related attitudes. However, this may have been due to ceiling effects, since most participants already reported high agreement with the attitude questions in the preshow condition. Furthermore, unlike Study 1, the play led to a marginal increase in altruistic values and no effect on social dominance orientation. These different results may have been due to differing content of the plays: for instance, "Skeleton Crew" touched more on the issue of societal inequality, which may explain why that play, and not "Wolf Play," impacted social dominance orientation.

\section{Internal Meta-Analysis and Integrative Data Analysis}

Because all studies used a similar design to test the same questions, we ran an internal meta-analysis to test the overall effect sizes (Goh, Hall, \& Rosenthal, 2016). All analyses were conducted using the SPSS Macro MeanES (Wilson, 2005). The effect sizes reported in Table 1 were used for the meta-analysis, and inverse variances were used as the weights. We used fixed effects models as a more conservative test of effect sizes and because of variability across studies. 
Table 1. Summary of Findings Across All Studies.

\begin{tabular}{ccccc}
\hline Study & Measure & $p$ & Effect size $(d)$ & Narrative Transportation $(r)$ \\
\hline $1 \mathrm{a}(\mathrm{n}=695)$ & Attitudes & $<0.001$ & 0.29 & $0.22^{* *}$ \\
& Empathy & $<0.001$ & 0.6 & $0.35^{* *}$ \\
& Charity & $<0.001$ & 0.3 & $0.26^{* *}$ \\
$1 \mathrm{~b}(\mathrm{n}=308)$ & Attitudes & 0.076 & 0.2 & $0.32^{* *}$ \\
& Empathy & 0.178 & 0.16 & $0.25^{* *}$ \\
$2(\mathrm{n}=619)$ & Attitudes & 0.573 & 0.05 & $0.32^{* *}$ \\
& Empathy & 0.004 & 0.23 & $0.46^{* *}$ \\
& Charity & $<0.001$ & 0.27 & $0.16^{* *}$ \\
\hline
\end{tabular}

Note: "Attitudes" is the mean effect of theatre on all socio-political opinions tested in the study, "Empathy" is the mean effect of theatre on empathy for groups depicted in the show, and "Charity" is the effect of theatre on interest in supporting a charity (Study 1), and charitable donation behavior (Study 3). In Study 3, participants were given the opportunity to donate to two different charities (related or unrelated), and the average score of both charities is reported in this table. Correlations between the main outcome variables and narrative transportation are also shown. $* *=p<0.01$.

As shown in Table 2, when meta-analyzed across studies, seeing theatre led people to change their attitudes about socio-political issues related to the show, Mean $E S=0.16,95 \% \mathrm{CI}=$ $[.01, .34], z=2.13, p=0.034$, feel more empathy for groups depicted in the show, Mean ES= $0.33,95 \% \mathrm{CI}=[.06, .60], z=2.41, p=0.016$, and donate more or express more interest in donating to charity after seeing the show, Mean $E S=0.28,95 \% \mathrm{CI}=[.18, .37], z=5.65, p<$ 0.001 .

Table 2. Internal Meta-Analysis.

\begin{tabular}{ccccc}
\hline Outcome Variable & $\mathrm{n}$ & Effect size $(d)$ & $p$ & $95 \% \mathrm{CI}$ \\
\hline Attitudes & 3 & 0.16 & 0.034 & {$[.01, .34]$} \\
Empathy & 3 & 0.33 & 0.016 & {$[.06, .60]$} \\
Charity & 2 & 0.28 & $<0.001$ & {$[.18, .37]$} \\
\hline
\end{tabular}

Note. Mean effect sizes and confidence intervals meta-analyzed across all studies. 


\section{Attitudes}

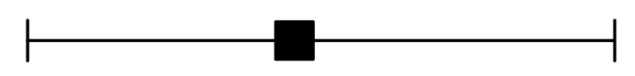

Empathy

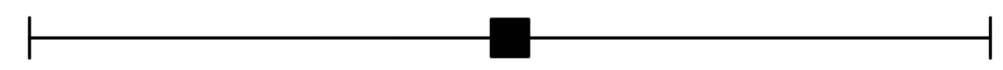

Charity

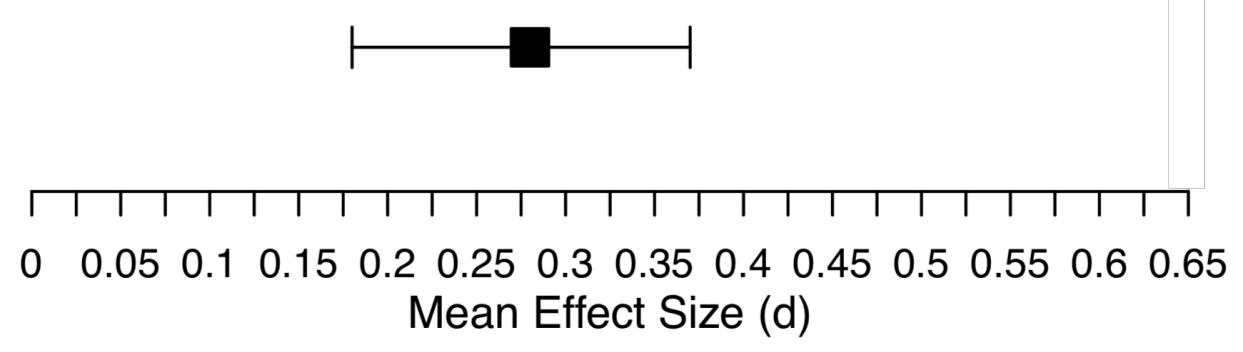

Figure 5. Graphical representation of the meta-analyzed effect sizes and confidence intervals reported in Table 2.

Since effect sizes likely vary considerably based on the content of a play, it is difficult to estimate an average effect size for theatre in general. Additionally, effect sizes of Study 1b were also likely dampened due to audience members being surveyed two days after the show.

Nevertheless, this internal meta-analysis, in addition to the previous table of effect sizes, bolsters the hypotheses that theatre productions can boost empathy, encourage pro-social behavior, and change people's attitudes about socio-political issues related to the plays.

In addition to an internal meta-analysis, we also performed an integrative data analysis (pooling data from all three studies) which allowed us to test additional questions with higher power. In particular, we tested for the interaction we found in Study $1 \mathrm{~b}$ between condition and political orientation on attitudes (see Figure S2). Here, the interaction between political orientation and condition was marginal, $B=0.02, S E=0.01, p=0.090$. Notably, while we did 
not find strong evidence for an interaction effect, we also did not find evidence for a backfire effect among conservative participants, suggesting that theatre can be a compelling vehicle for attitude change even among those who disagree politically with the typically liberal viewpoint of theatre.

We also conducted additional analyses to examine differences in demographics across conditions. Importantly, we did not find any meaningful demographic differences between conditions across all studies, meaning that we had good randomization across conditions (See Table S2). We found only minor demographic differences between matinee and non-matinee attendees (See Table S1), which is to be expected given the tendency for both older individuals and students to attend matinees. Lastly, to assuage any concerns about demographic confounds, we conducted multiple regression analyses with the pooled data testing the effects of seeing theatre while controlling for several demographic variables (e.g., age, gender, income, education, political orientation, how often someone attends the theatre, and whether the theatre-goer was attending a matinee). Even when accounting for all demographic controls, seeing theatre still had a robust effect on across outcome variables.

\section{General Discussion}

Across three field studies, including one pre-registered replication, we found evidence that attending a live theatre production increased audience members' empathy for groups depicted in the play, changed their opinions about socio-political issues, and led to increases in charitable donations to causes both related to the play and unrelated to the play. These effects were correlated with how transported theatre-goers were by the performances and were mediated by the amount of empathy the plays evoked for groups depicted in the show. 
These findings offer novel insight into the role of narrative arts in shaping empathy. By demonstrating that consuming theatre enhances empathy, our findings connect past literature demonstrating that consuming fiction and acting improve empathy. They suggest a broad role of the narrative arts in influencing empathy above and beyond processes specific to one modality, with narrative transportation serving as a common mechanism. Finally, these findings offer meaningful real-world implications, given the millions of people who view theatre each year.

While the quasi-experimental field experiment design provided a number of benefits, such as testing our hypotheses with high-power in a naturalistic environment, it also has limitations. For instance, it is unclear to what extent the "live" component of theatre potentially contributes to these effects. Past research demonstrates that sharing an experience with others amplifies the intensity of that experience (Boothby et al., 2014); it is therefore possible that live theatre may be more compelling than watching a movie or reading a piece of narrative fiction. Additionally, live theatre may feel more immersive than film or fiction, since actors are performing in front of audience members. Here, we did not test how live theatre compares to other artforms, instead aiming to first establish in a high-powered, large-scale sample that theatre has an effect at all, since this question has not been adequately answered in the literature. Future research can shed more light on the mechanisms behind these effects, including investigating whether the mere presence of others can amplify the effects found in these studies.

While the effect sizes of the present studies may be considered small-to-moderate by traditional standards (Funder \& Ozer, 2019, though see also Lovakov \& Agadullina, 2021), they are in the range of what would be expected considering past research on fiction and empathy. Indeed, a meta-analysis of all studies looking at fiction's effects on social cognition found a small effect size of Hedges $G=0.15-0.16$ (Dodell-Feder \& Tamir, 2018) - somewhat lower than 
the effect sizes found in the present studies (Cohen's $D=.16-.33$ ). Additionally, a small-tomoderate increase in charitable donation behavior or change in one's political attitudes is practically significant, given the tens of millions of people who attend theatre each year. Finally, it should be noted that there was some heterogeneity of effect sizes across studies, with "Skeleton Crew" leading to larger effects than "Wolf Play," and "Wolf Play" having a null effect on the "attitudes" measure. These differences could be attributable to differences in the content explored in the plays, or differences in the attitude questions chosen for the plays. For instance, the null effect on attitudes in "Wolf Play" may be due to the fact that the pre-show group already had very high agreement with all of the attitude questions, leaving less room for attitude change. Nonetheless, although effect sizes differed somewhat across studies, they were largely consistent and remained robust when considering various demographic control variables. Thus, these findings demonstrate the potential for multiple different plays to promote empathy, pro-social behavior, and attitude change in different contexts.

Future research can also examine the long-term effects of theatre. Here, we found some suggestive evidence that the effects of theatre persist over time among a small sample of participants (see Study 2 Supplemental Results); in addition, correlational evidence indicated that those who attended theatre more often tended to score higher in measures of empathy and prosocial behavior. Nonetheless, more data should be collected to address this question. Lastly, while we found effects of theatre across multiple plays with different content, theatre is not one thing, and future studies can expand on this work by studying the effects of different theatrical productions. Since we specifically selected plays that we expected would improve empathy toward disadvantaged groups, it is unclear whether these results would hold for plays that do not 
intuitively seem to evoke empathy (e.g., a fairy tale). ${ }^{1}$ Future studies should examine the boundary conditions of these effects and whether they are generalizable to different forms of theatre. However, we expect that the persuasive effects of narratives can apply to a broad array of stories, as long as people are sufficiently transported by these stories. Evidence from fiction shows that many types of stories, even those thought to be mostly for entertainment, can have persuasive or empathy-inducing effects. For induce, reading Harry Potter led children to express more positive attitudes toward stigmatized groups, such as immigrants (Vezzali et al., 2015). Though, while narratives are persuasive, they are not universally positive - they can also mislead or be used for propaganda (Van Bavel et al., 2021). Thus, while we expect much of theatre to be persuasive about topics depicted in a show (or even evoke generalized pro-social behavior, as in Study 3), the specific effects of theatre will likely vary widely across shows.

Notably, theatre-goers in the present study self-selected into attending theatre, and many of them had the finances or interest to attend theatre (although all performances in Study $1 \mathrm{~b}$ were free, and both theatres make efforts to reach out to diverse audiences). Thus, the audience members who choose to attend theatre may be more open to attitude change, based on their ability and motivation to attend theatre. We also found that audience members tended to be older, more liberal, and have relatively high levels of income and education (see Table S2 for additional demographics). However, results did not depend on demographic factors and remained robust when controlling for all demographic variables (Table S4). In fact, in Study 1b,

\footnotetext{
${ }^{1}$ Notably, the plays we tested addressed primarily liberal themes, which is true of most plays (for more, see reporting on the "Stage Right," which is one of the rare festivals in America that has plays with conservative themes: https://www.americantheatre.org/2017/10/24/enter-stage-right/). Thus, while we only tested our questions in the context of more liberal plays, conservative-leaning plays are extremely rare. Additionally, the effects of theatre did not backfire and were potentially stronger for more conservative participants. In light of these findings, a play that touches on conservative themes might similarly impact liberal participants without backfire effects, as long as that play effectively evoked a sense of a narrative transportation. As noted earlier, one small-scale study found that watching a musical about hunting improved attitudes about hunting, a more conservative topic (Heide et al., 2012).
} 
we found that attitude change was more effective for conservative participants, although this effect was only marginal in the integrative data analysis. Altogether, the effects of theatre do not appear to depend on demographic factors among theatregoers. Thus, theatre may be an effective tool to change attitudes or increase pro-sociality for a wide range of individuals, suggesting that efforts to reach populations that do not normally attend theatre may be beneficial.

Psychologists have long been interested in interventions that can improve empathy and reduce prejudice (Paluck et al., 2020; Weisz \& Zaki, 2017), and this research sheds light on the potential role that theatre and the arts could play in such interventions. Providing more opportunities to access theatre and the arts can even be seen as a scalable empathy intervention, generating the type of effect psychologists might try to devise in lab experiments. Additionally, theatre is a major - yet understudied - part of people's lives: in the 2018-2019 season, audience members spent $\$ 18$ billion on tickets to plays and musicals on Broadway (Broadway League, 2018). While the path to theatres re-opening is currently uncertain, and arts funding is often threatened (Cowen, 2009), these studies provide evidence for the tangible impact of theatre. They demonstrate the value of the theatre and the arts as not only a form of entertainment, but also as a tool for improving empathy and pro-social behavior, and a potential vehicle for social change. 


\section{Open Practices Statement}

Materials, data, and code for these studies are available here: https://osf.io/kcj9t/.

The pre-registration is available here: https://aspredicted.org/blind.php? $\mathrm{x}=423 \mathrm{xz} 3$. 


\section{References}

Appel M., Gnambs T., Richter T., Green M. C., The transportation scale-short form (TS-SF) Media Psychology 2015 243-266

Batson, C. D., Chang, J., Orr, R., \& Rowland, J. (2002). Empathy, attitudes, and action: Can feeling for a member of a stigmatized group motivate one to help the group? Personality and Social Psychology Bulletin, 28(12), 1656-1666.

Batson, C. D., Polycarpou, M. P., Harmon-Jones, E., Imhoff, H. J., Mitchener, E. C., Bednar, L. L., Klein, T. R., \& Highberger, L. (1997). Empathy and attitudes: Can feeling for a member of a stigmatized group improve feelings toward the group? Journal of Personality and Social Psychology, 72(1), 105.

Bazalgette, P. (2017). The empathy instinct: How to create a more civil society. Hachette UK. Boothby, E. J., Clark, M. S., \& Bargh, J. A. (2014). Shared experiences are amplified. Psychological Science, 25(12), 2209-2216.

Bushman, B. J., \& Anderson, C. A. (2009). Comfortably numb: Desensitizing effects of violent media on helping others. Psychological Science, 20(3), 273-277.

Cowen, T. (2009). Good and plenty: The creative successes of American arts funding. Princeton University Press.

Davis, M. H. (1983). Measuring individual differences in empathy: Evidence for a multidimensional approach. Journal of Personality and Social Psychology, 44(1), 113.

Deb, S. (2017). Trump proposes eliminating the arts and humanities endowments. The New York Times, 15 March 2021. https:/www.nytimes.com/2017/03/15/arts/nea-neh-endowmentstrump.html

Dodell-Feder, D., \& Tamir, D. I. (2018). Fiction reading has a small positive impact on social 
cognition: A meta-analysis. Journal of Experimental Psychology. General, 147(11), 1713-1727. https://doi.org/10.1037/xge0000395

Eustis, O. (2018). Why theater is essential to democracy. Ted Talk.

https://www.ted.com/talks/oskar_eustis_why_theater_is_essential_to_democracy

Faul, F., Erdfelder, E., Lang, A.-G., \& Buchner, A. (2007). G* Power 3: A flexible statistical power analysis program for the social, behavioral, and biomedical sciences. Behavior Research Methods, 39(2), 175-191.

Fiedler, K., Harris, C., \& Schott, M. (2018). Unwarranted inferences from statistical mediation tests-An analysis of articles published in 2015. Journal of Experimental Social Psychology, 75, 95-102.

Fiedler, K., Schott, M., \& Meiser, T. (2011). What mediation analysis can (not) do. Journal of Experimental Social Psychology, 47(6), 1231-1236.

Funder, D. C., \& Ozer, D. J. (2019). Evaluating effect size in psychological research: Sense and nonsense. Advances in Methods and Practices in Psychological Science, 2(2), 156-168.

Garver, K. (2019). BWW Review: Artists Rep Scores a Knockout with World Premiere of Hansol Jung's WOLF PLAY. BroadwayWorld.Com.

https://www.broadwayworld.com/portland/article/BWW-Review-Artists-Rep-Scores-aKnockout-with-World-Premiere-of-Hansol-Jungs-WOLF-PLAY-20190319

Goh, J. X., Hall, J. A., \& Rosenthal, R. (2016). Mini meta-analysis of your own studies: Some arguments on why and a primer on how. Social and Personality Psychology Compass, 10(10), $535-549$.

Goldstein, T. R., \& Winner, E. (2012). Enhancing empathy and theory of mind. Journal of Cognition and Development, 13(1), 19-37. 
Goldstein, T. R., Wu, K., \& Winner, E. (2009). Actors are skilled in theory of mind but not empathy. Imagination, Cognition and Personality, 29(2), 115-133.

Green, M. C., \& Brock, T. C. (2000). The role of transportation in the persuasiveness of public narratives. Journal of Personality and Social Psychology, 79(5), 701.

Greene, J. P. (2015). Learning from live theater: Students realize gains in knowledge, tolerance, and more. Education Next, 15(1), 55-63.

Harvey, M. L., \& Miles, D. (2009). And then they came for me: The effectiveness of a theatrical performance and study guide on middle-school students' Holocaust knowledge and empathic concern. Youth Theatre Journal, 23(2), 91-102.

Hayes, A. F. (2017). Introduction to mediation, moderation, and conditional process analysis: A regression-based approach. Guilford Publications.

Heide, F. J., Porter, N., \& Saito, P. K. (2012). Do you hear the people sing? Musical theatre and attitude change. Psychology of Aesthetics, Creativity, and the Arts, 6(3), 224.

Hessling, R. M., Traxel, N. M., \& Schmidt, T. J. (2004). Ceiling effect. Encyclopedia of Social Science Research Methods, 1, 106.

Kidd, D. C., \& Castano, E. (2013). Reading literary fiction improves theory of mind. Science, 342(6156), 377-380.

Koopman, E. M. E. (2015). Empathic reactions after reading: The role of genre, personal factors and affective responses. Poetics, 50, 62-79.

Kou, X., Konrath, S., \& Goldstein, T. R. (2019). The relationship among different types of arts engagement, empathy, and prosocial behavior. Psychology of Aesthetics, Creativity, and the Arts. Kushner, R. (2016). National Arts Index 2016: An Annual Measure of the Vitality of Arts and Culture in the United States. Americans for the Arts. https://www.americansforthearts.org/by- 
program/reports-and-data/legislation-policy/naappd/national-arts-index-an-annual-measure-ofthe-vitality-of-arts-and-culture-in-the-united-states-2016

League, B. (2018). Broadway Season Statistics. Broadway League.

https://www.broadwayleague.com/research/statistics-broadway-nyc/

Mar, R. A., \& Oatley, K. (2008). The function of fiction is the abstraction and simulation of social experience. Perspectives on Psychological Science, 3(3), 173-192.

Mar, R. A., Oatley, K., \& Peterson, J. B. (2009). Exploring the link between reading fiction and empathy: Ruling out individual differences and examining outcomes. Communications, 34(4), 407-428.

Mazzocco, P. J., Green, M. C., Sasota, J. A., \& Jones, N. W. (2010). This story is not for everyone: Transportability and narrative persuasion. Social Psychological and Personality Science, 1(4), 361-368.

McGlone, P. (2020). Trump budget again calls for the elimination of federal arts agencies. Washington Post. https://www.washingtonpost.com/entertainment/trump-budget-again-calls-forthe-elimination-of-federal-arts-agencies/2020/02/10/8b9e8df2-4c4f-11 ea-bf44f5043eb3918a_story.html

Mosle, S. (2012). What should children read. New York Times. http://opinionator.blogs.nytimes.com/2012/11/22/what-should-children-read/?r=1. Nettle, D. (2006). Psychological profiles of professional actors. Personality and Individual Differences, 40(2), 375-383.

Paluck, E. L., Porat, R., Clark, C. S., \& Green, D. P. (2020). Prejudice reduction: Progress and challenges. Annual Review of Psychology, 72.

Panero M. E., Weisberg D. S., Black J., Goldstein T. R., Barnes J. L., Brownell H., Winner E., 
Does reading a single passage of literary fiction really improve theory of mind? An attempt at replication Journal of Personality and Social Psychology 2016 e46

Pratto, F., Sidanius, J., Stallworth, L. M., \& Malle, B. F. (1994). Social dominance orientation: A personality variable predicting social and political attitudes. Journal of Personality and Social Psychology, 67(4), 741.

Samur, D., Tops, M., \& Koole, S. L. (2018). Does a single session of reading literary fiction prime enhanced mentalising performance? Four replication experiments of Kidd and Castano (2013). Cognition and Emotion, 32(1), 130-144.Chicago

Smith, T. W. (2003). Altruism in contemporary America: A report from the National Altruism Study. Available: http://www-news.uchicago.edu/releases/03/altruism.pdf

Soloski, Alexis. Playwright Dominique Morisseau Can’t Forget the Motor City (2015). New York Times. 28 July 2019

Spencer, S. J., Zanna, M. P., \& Fong, G. T. (2005). Establishing a causal chain: Why experiments are often more effective than mediational analyses in examining psychological processes. Journal of Personality and Social Psychology, 89(6), 845.

Van Bavel, Reinero D. A., Spring V., Harris E. A., Duke A., Speaking my truth: Why personal experiences can bridge divides but mislead Proceedings of the National Academy of Sciences 2021

Van de Vyver, J., \& Abrams, D. (2018). The arts as a catalyst for human prosociality and cooperation. Social Psychological and Personality Science, 9(6), 664-674.

Van Kuijk, I., Verkoeijen, P., Dijkstra, K., Zwaan, R. A., Vazire, S., \& Vul, E. (2018). The effect of reading a short passage of literary fiction on theory of mind: A replication of Kidd and Castano (2013). Collabra: Psychology, 4(1). 
Van Laer, T., De Ruyter, K., Visconti, L. M., \& Wetzels, M. (2013). The extended transportation-imagery model: A meta-analysis of the antecedents and consequences of consumers' narrative transportation. Journal of Consumer Research, 40(5), 797-817. Vezzali, L., Stathi, S., Giovannini, D., Capozza, D., \& Trifiletti, E. (2015). The greatest magic of Harry P otter: Reducing prejudice. Journal of Applied Social Psychology, 45(2), 105-121.

Weisz, E., \& Zaki, J. (2017). Empathy building interventions: A review of existing work and suggestions for future directions. The Oxford Handbook of Compassion Science, 205-217. Wilson, D. B. (2005). Meta-analysis macros for SAS, SPSS, and Stata. 